\title{
Analysis of the Pulp Chamber Temperature of Teeth Submitted to LightActivation with and without Bleaching Gel
}

\author{
${ }^{1}$ Graziela Ribeiro Batista, ${ }^{1}$ Daphne Câmara Barcellos, ${ }^{2}$ Alessandra Bühler Borges \\ ${ }^{2}$ Carlos Rocha Gomes Torres \\ ${ }^{1}$ Postgraduate Student, Clinical Research Academic Group, São José dos Campos School of Dentistry, São Paulo \\ State University, UNESP, São Paulo, Brazil \\ ${ }^{2}$ Assistant Professor, Department of Restorative Dentistry, São José dos Campos School of Dentistry, São Paulo \\ State University, UNESP, São Paulo, Brazil
}

Correspondence: Carlos Rocha Gomes Torres, Avenida Engenheiro Francisco José Longo, 777, Jardim São Dimas, São José dos Campos, São Paulo, CEP 12245-000, Brazil, Phone: +55 (12) 3947 9052, Fax: +55 (12) 3947 9010, e-mail: carlosrgt@ fosjc.unesp.br

\section{ABSTRACT}

Purpose: This study evaluated the temperature of the pulpal chamber $(P C)$ of teeth submitted to the light activation with and without bleaching gel, using different types of light sources.

Materials and methods: A digital thermometer, thermocouple $\mathrm{K}$ type, was located in the PC of human upper central incisors and the specimens received light activation from the following sources: G1-Laser, G2-Halogen light, G3- progressive intensity halogen lamp, G4-LED/Laser. The light was applied for 3 minutes, with and without the use of bleaching gel. The data were collected after every 30 seconds and analyzed by three-way ANOVA and Tukey's test.

Results: The mean values were: Use of the gel-with gel: 3.09a, without gel: 2.79b; Type of light source-G 1: 0.60a, G2: 2.38b, G3: 4.16c, G 4: 4.63d; Time of activation 30 seconds: 1.15a, 1 minutes: 2.20b, 1 minutes 30 seconds: 2.97c, 2 minutes: $3.44 d$, 2 minutes 30 seconds: 3.81e, 3 minutes: $4.09 \mathrm{e}$

Conclusions: The use of bleaching gel associated with light activation resulted in higher heating of the PC. LED/LASER light and progressive intensity halogen lamp showed highest levels of heating. The increase of irradiation time significantly increased the temperature.

Keywords: Temperature, Dental pulp, Dental bleaching.

\section{INTRODUCTION}

The in-office tooth bleaching technique is based on the application of high concentration hydrogen peroxide gel, about $35 \%$, which is applied on the teeth during a period of 30 to 60 minutes, and the application of this gel can be combined to the activation by different light sources in order to accelerate the bleaching process. ${ }^{1,2}$ This acceleration occurs because the pigments present in the gel are capable to absorb the light generated by different devices, increasing the temperature of bleaching gel and consequently accelerating the bleaching process. ${ }^{3} \mathrm{H}$ owever, this temperature increase al so occurs inside the pulp chamber, which could cause pulpal injuries, making this technique impracticable.

Some light devices are commonly used by professionals for the activation of the bleaching gel, however, these units are safe for use as a resin curing light, ${ }^{4}$ considering that the light is applied directly on the tooth just over seconds. The risk of heating results in pulpal damage but is not so expressive as in bleaching treatment, when the light is applied over a layer of gel that improves light absorption and promote the conversion of light energy into heat, resulting in critical high temperatures values, unsafe for the pul pal vitality maintenance., ${ }^{5,6}$

Based on these facts, the objective of this study was to evaluate the temperature of the pulp chamber of teeth submitted to light activation with and without bleaching gel, using different types of light sources. The null hypothesis assessed is that the use of gel does not promote significant differences in temperature increase and that the different light sources do not promote significant heating. It was also eval uated in the hypothesis that temperature does not show variations over the light activation period.

\section{MATERIALS AND METHODS}

To perform this study, 80 upper central incisors were used. Conventional endodontic accesses were made through the lingual face of each tooth, using high speed spherical diamond burs, and the pulpal tissue was removed with endodontic files. The buccal face thickness was standardized to simulate the dentin thickness of young adults, using low speed spherical diamond burs. ${ }^{4}$ The pulp chamber was filled with zinc oxide thermal paste (I mplastec, V otorantim, SP, B razil) in order to simulate the heat dissipation that would occur through the pulp tissue. ${ }^{4} \mathrm{~A}$ type $\mathrm{K}$ thermocouple sensor was immersed in thermal paste, touching internal part of buccal face, to measure intrapul pal temperature. This sensor was connected to a digital thermometer (M T-507, M inipa L tda, São Paulo, B razil) and temperature measurements were recorded for every 30 seconds over 3 minutes while the light source was used. All tests were performed at room temperature of $37^{\circ} \mathrm{C}$.

Four groups $(n=20)$ were analyzed, for each one a different light device was used, as shown in Table 1. Each group was 
divided into two subgroups ( $n=10)$, according the use or not of bleaching gel associated to light activation. For the groups with gel association, $2 \mathrm{~mm}$ layer of $35 \%$ hydrogen peroxide bleaching gel (Total B leach, Clean Line, T aubaté, São Paulo, Brazil) was applied on buccal surfaces according to the manufacturer's specifications. The red light emitting device (B right M ax, Clean L ine, Taubaté, São Paulo, B razil) was used in association with green color gel. For blue light emitting devices, the orange color gel was used. ${ }^{7}$ The light-emitting tip was positioned to $1 \mathrm{~cm}$ from the tooth surface. The variation of pulpal temperature was calculated and the data were analyzed by three-way A NOVA and Tukey's test ( $\alpha=5 \%)$.

\section{RESULTS}

A N OV A showed $p$-values $=0.001$ for all factors analyzed that were: presence of bleaching gel (1), type of light source (2) and light activation period (3) and also for interaction between factors 1 and 2 and factors 1 and 3 . For the interaction between factors 2 and 3 , the $p$-value $=0.17$ and for interaction among the three factors $p$-value $=0.99$.

Tables 2, 3 and 4 show the results of the Tukey's test for the factors evaluated. The use of gel increased intrapulpal temperature(Table2). Table 3 shows that the LED/L aser (E asy
Bleach) and progressive intensity halogen lamp (J et L ite) were responsible for the higher values of pulpal chamber greater heating. In Table 4, it is possible to see that as longer is the light activation period, higher is the pul pal chamber temperature. Graph 1 shows the increase of temperature over time of irradiation. Higher results of intrapul pal heating was obtained for the group that associated bleaching gel and blue LED/Laser light (Easy Bleach). For all tested groups, the intrapulpal temperature increased proportionally to the time of irradiation.

\section{DISCUSSION}

The chemical decomposition of hydrogen peroxide releases free radicals of oxygen that has high oxidative capacity. Due to this characteristic, these radicals promote the breakdown of pigments present in tooth structure and results in bleaching. ${ }^{8}$ Previous study ${ }^{9}$ showed that for high temperatures, the chemical decomposition of peroxide is also increased, according to the rule described by $V$ an' $t H$ off, that rel ates changes in temperature according to the variation of constant equilibrium of the hydrogen peroxide decomposition reaction. Important studies ${ }^{5,10}$ explained that with each $10^{\circ} \mathrm{C}$ increase in temperature, the chemical decomposition of hydrogen peroxide increased by 2.2 to 2.5 times. In 1979, it was stated that

Table 1: Different groups and light devices evaluated

\begin{tabular}{lll} 
Device & \multicolumn{1}{c}{ Light type } & Manufacturer \\
\hline Easy Bleach & $\begin{array}{l}\text { 2 LEDs of } 500 \mathrm{~mW} \text { emitting blue light }(\lambda=470 \mathrm{~nm}) \\
\text { and } 1 \text { diode laser of } 120 \mathrm{~mW} \text { emitting infrared }(\lambda=784 \mathrm{~nm})\end{array}$ \\
$\begin{array}{ll}\text { Bright Max } \\
\text { Curing Light XL } 3000\end{array}$ & Halogen lamp $550 \mathrm{~mW}$ emitting blue light $(\lambda=450 \mathrm{~nm})$ & Clean line, Taubaté, SP, Brazil \\
Jet Light 4000 Plus & Halogen lamp with progressive increase in power density & 3M ESPE, Grafenau, Germany \\
& $100-1400 \mathrm{~mW}$ emitting blue light $(\lambda=500 \mathrm{~nm})$ & J Morita, Osaka, Japan
\end{tabular}

\begin{tabular}{|c|c|c|}
\hline Use of gel & Means ( $\pm S D)$ & $\begin{array}{l}\text { Homogeneous } \\
\text { groups* }\end{array}$ \\
\hline With gel & $3.09( \pm 2.03)$ & A \\
\hline Without gel & $2.79( \pm 2.26)$ & B \\
\hline
\end{tabular}

*The means followed by different letters (homogeneous groups) present significant statistical differences for the test of Tukey $(p<0.05)$

Table 3: Mean and SD values of the temperature rise in the pulp chamber for samples irradiated with different devices

$\begin{array}{llc}\text { Type of device } & \text { Means }( \pm S D) & \begin{array}{c}\text { Homogeneous } \\ \text { groups* }\end{array} \\ \text { Brite Max } & 0.60( \pm 0.43) & \mathrm{A} \\ \text { Curing Light XL } 3000 & 2.38( \pm 1.31) & \mathrm{B} \\ \text { Jet Lite } 4000 \text { Plus } & 4.16( \pm 1.60) & \mathrm{C} \\ \text { Easy Bleach } & 4.63( \pm 1.67) & \mathrm{D} \\ \text { *The means followed by different letters (homogeneous groups) } \\ \text { present significant statistical differences for the test of Tukey } \\ \text { ( } p<0.05)\end{array}$

Table 4: Mean and SD values of the temperature rise in the pulp chamber at different times

\begin{tabular}{|c|c|c|}
\hline Time of light activation & Means $( \pm S D)$ & $\begin{array}{l}\text { Homogeneous } \\
\text { groups* }\end{array}$ \\
\hline 30 seconds & $1.15( \pm 0.76)$ & $A$ \\
\hline 1 minute & $2.20( \pm 1.33)$ & B \\
\hline 1 minute 30 seconds & $2.97( \pm 1.77)$ & C \\
\hline 2 minutes & $3.44( \pm 2.07)$ & D \\
\hline 2 minutes 30 seconds & $3.81( \pm 2.33)$ & E \\
\hline 3 minutes & $4.09( \pm 2.57)$ & $E$ \\
\hline
\end{tabular}

*The means followed by different letters (homogeneous groups) present significant statistical differences for the test of Tukey $(p<0.05)$ 
Analysis of the Pulp Chamber Temperature of Teeth Submitted to Light Activation with and without Bleaching Gel

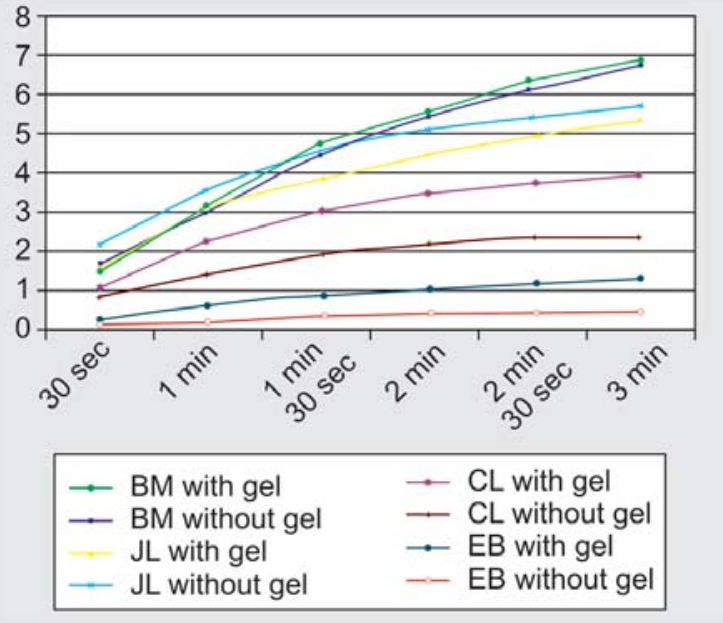

Graph 1: Temperature rise in the pulp chamber over time. BM: Bright Max; JL: Jet Light 4000 Plus; CL: Curing Light XL3000; EB: Easy Bleach

bleaching is improved by the use of heat ${ }^{11}$ and the better efficient temperature of bleaching agent for use in vital teeth ranges between 46 to $60^{\circ} \mathrm{C} \cdot{ }^{12} \mathrm{~A}$ s temperature is increased the diffusion of hydrogen peroxide on enamel and dentin is al so increased. ${ }^{13}$

However, the use of light activation may result in excessive el evation of temperature and it may cause pulpal damage. Zach and Cohen ${ }^{14}$ observed in a study invivo performed in monkeys, that increase of $5.5^{\circ} \mathrm{C}$ resulted in $15 \%$ of teeth with irreversible pulp damages, and for increases around $11.1^{\circ} \mathrm{C}$ this risk is $60 \%$. B aik et a ${ }^{15}$ observed that the use of light activation with hal ogen lamp or appliance of plasma arc light resulted in pulpal heating from 5 to $8^{\circ} \mathrm{C}$, which was over the limit established by Zach and Cohen ${ }^{14}$ and could cause irreversible pulpal damages.

There are three theories that attempt to explain the action of light in accelerating the decomposition of hydrogen peroxide. The first rel ates to a controlled heating of the bleaching gel, the second refers to an electronic excitation of molecules of hydrogen peroxide, while the third suppose a photochemical action of the pigment.

A ccording to the first theory, when the light is absorbed by the bleaching gel, the radiant energy is converted into thermal energy (heat). ${ }^{5}$ This transformation is called photothermal effect. ${ }^{4}$ Previous study ${ }^{9}$ showed that this is the most important effect of photocatalytic bleaching procedures. Some authors stated that the heating of hydrogen peroxide is able to accel erate its decomposition reaction and formation of radical oxidants. ${ }^{10,12,16}$ F urthermore, the increase in temperature promotes a bigger diffusion of hydrogen peroxide through enamel and dentin, ${ }^{17,18}$ thus faster penetration may be associated to the use of light devices. ${ }^{5}$

The second theory states that the action of light for bleaching agents activations may produce nonthermal effects on the chemical, known as photochemical effects, photolysis or photodissociation. A ccording to $\mathrm{Crim},{ }^{19}$ photons can produce an electronic excitement and/or vibration in the molecules, causing the disruption in certain chemical bonds intramolecular and intermolecular. The change of vibrational state of molecules requires the deposition of a relatively large amount of energy, which can be provided by high-energy photons. This can promote the decomposition of hydrogen peroxide. ${ }^{20}$

Finally, third theory of action of light on the bleaching gels states about the physicochemical interactions with the pigment, that interfere to the hydrogen peroxide stability. There are reports in the literature that substances as carotene, annatto, $\mathrm{SiO}_{2}$ and $\mathrm{TiO}_{2}$, present in the composition of bleaching gels, when irradiated with light, can be dissociated or suffer alterations, changing their electrical charges and resulting in destabilization of the hydrogen peroxide or disbal ance the $\mathrm{pH}$ of the whitening gel. Chen et $\mathrm{al}^{21}$ found that rapid changes in $\mathrm{pH}$ cause a destabilization in the molecule of hydrogen peroxide and results in the release of free radicals.

The null hypothesis, that the use of gel with light activation does not promote significant differences in temperature, was rejected because there was statistically significant differences for pulpal temperature increase to the groups where the bleaching gel was used in relation to groups where only light activation was performed. A ccording to the literature, the use of light activation for whitening gel generates higher intrapul pal temperature heating, ${ }^{5,22-25}$ which is also proved through this study. This suggests that the photothermal effect occurred when light activation was used associated to bleaching gel .

Previous study ${ }^{24}$ showed difference between surface temperature and pul pal chamber temperature for teeth submitted to bleaching with and without the use of bleaching gel, and was stated that the gel had an insulating effect on the temperature increase, and the use of the gel would serve as a protective layer minimizing the increase of intrapulpal temperature. It was al so shown that the presence of the gel reduced the magnitude of temperature increase, but when using the diode laser device temperature was significantly increased, more than for other types of devices used. ${ }^{26} \mathrm{Y}$ azici et al ${ }^{27}$ demonstrated that the association of source of light energy with the use of whitening gel creates a potential increase in intrapul pal temperature. This factor possibly occurs due to the combination of heat generated by infrared radiation and visible light absorption by the pigments present in the bleaching gel..$^{28,29}$

However, changes in temperature increase are directly dependent on type of light used and light irradiation time that specimens are submitted, and although this study has been performed only for the upper central incisors, it is still possible that the temperature variation may al so occur due to anatomical differences of each specimen, and different thicknesses of dentin and enamel in the various specimens used, which is also a factor influencing the increase in intrapulpal temperature. ${ }^{4}$ This study was based on the methodology described by Torres et al ${ }^{4}$ and B aik et al ${ }^{15}$ that standardized the thickness of the buccal face, simulating the thickness of dentin of young adults teeth, to minimize the possible variation in results.

The null hypothesis that different devices do not promote significant heating has been rejected. In this study, the device LED/Laser Easy Bleach with blue LEDs and a diode laser 
showed higher results for intrapul pal heating. A surprising result because in these hybrid devices the main source of energy to catalyze the reaction of bleaching comes from LEDs, emitting visible light. These devices have a form of highly concentrated and selective energy and the radiation is emitted at a specific wavel ength. Thus, one can choose a predominance of thermal effects, using infrared radiation or a light more cool in the visible spectrum. The emission of light by the LED s is concentrated in a narrow band of 20 to $80 \mathrm{~nm}$.

The laser diodes present in these devices emit infrared radiation wavel ength. A Ithough these waves have the ability to produce some increase in temperature of the gel and help to accelerate the decomposition reaction of hydrogen peroxide, the main goal is to produce nonthermal effects on dental pulp, known as effects of biomodulation, in order to decrease the trans and postoperative sensitivity. For this reason, infrared laser diodes of low intensity, around 100 to $500 \mathrm{~mW}$ are used.

However, for the occurrence of a maximum absorption of the light emitted by the LED, pigments are added to the bleaching gels to act as selectors or filters absorbing one or more radiation and reflecting others. Thus, to enhance the absorption of light from LED/Laser Easy Bleach, bleaching gel containing orange pigment was used. Perhaps the combination of these two light sources and the process of luminescence emitting light in a specific wavel ength that is wider absorbed by the orange pigment into the bleaching gel can justify the results of this study. ${ }^{28,29}$

Castanho et $\mathrm{al}^{30}$ evaluated the influence of color gel in the temperature of the bleaching gel and pulp chamber, using activation with the blue light produced by LED devices. The authors observed that the red gels resul ted in significantly greater heating than the blue, confirming the relationship between color and energy absorption. Torres et al ${ }^{4}$ observed that the temperature of whitening gel layer is el evated when irradiated with light sources, maybe due to absorption of light by certain colors or due to the concentration of some products. Previously, ${ }_{17}^{17}$ it was reported that the application of blue light from different sources on a gel with pigment, resulted in temperature significantly higher than the absorption that occurs by gel without pigment. For equipment J et Light 4000 Plus and Curing Light XL 3000 that present bulb as a source of light activation, we observed mean temperature increase of 4.16 and $2.38^{\circ} \mathrm{C}$ respectively. A problem of these devices is the heating of the teeth due to the characteristics of the light produced. A ccording to Buchalla and A ttin, ${ }^{6}$ the wavelength emitted by these lamps ranges from the ultraviol et $(\lambda<380 \mathrm{~nm})$ across the visible spectrum $(\lambda=380-770 \mathrm{~nm})$ and penetrates deeply into the red $(\lambda>770 \mathrm{~nm})$. W hile there are filters that can minimize the arrival of the waves to the tooth, they are not completely eliminated, and a heating will al ways occur ${ }^{6}$ promoting a sum of heating, resulting from the infrared absorption of visible light by colored gels. ${ }^{17}$ It can also be observed in this study, that the unit Light J et 4000 Plus had a mean increase of intrapulpal temperature, statistically significant in relation to the unit C uring
Light XL 3000. This result is probably due to a power density of the device J et $L$ ight 4000 Plus, which can reach the val ue of $1400 \mathrm{~mW}$, while the unit Curing Light XL 3000 has a power density of up to $550 \mathrm{~mW}$. Therefore, most of the energy produced by hal ogen lamps consists of infrared radiation, also called thermal waves, and higher the power density, higher the energy that can generate an immediate heating of any object which is in contact.

Contradicting the findings of this study, another one ${ }^{31}$ evaluated that the temperature increases during the pulp bleaching procedure using light curing units with halogen lamps and hybrid device LED/L aser emitting blue light (E asy B leach). For activation with halogen J et Light (J M orita), sending a power density of $1200 \mathrm{~mW} / \mathrm{cm}^{2}$, there was a heating over the critical temperature of $5.5^{\circ} \mathrm{C}$ after 40 seconds irradiation. After 3 minutes and 20 seconds, the pulp temperature increased about $11^{\circ} \mathrm{C}$. On the other hand, for the device equipped with LEDs, the critical temperature was not reached in any period, even after 3 minutes and 20 seconds of irradiation, indicating bigger security for the use of these devices, so the light can be applied for longer times without risk of pulp damage. Similar results were observed by Eldeniz et al, ${ }^{32}$ who observed that the LEDs promoted the lower heating pulp in relation to the hal ogen lamps.

The device B right $M$ ax showed the lowest values of pulp temperature increase among the devices tested. This result may be because the device presents three lasers with a small power density of $50 \mathrm{~mW}$, and although these waves have the ability to produce some increase in temperature of the gel and help to accelerate the decomposition reaction of hydrogen peroxide, the main goal is to produce biomodulation effects.

The null hypothesis that the temperature does not vary with increasing time of irradiation was al so rejected. The results of this study showed that higher is period of light irradiation, higher is the increase of intrapulpal temperature because of the longer exposure of gel to light activation, therefore getting longer stimulus and then absorbing more light and generating more heat. This result can be strengthened by the results obtained before ${ }^{4}$ where bleaching gel was activated by LED/L aser and halogen light and the temperature was measured after each 40 seconds, and it showed temperature increases proportionally to the time of light exposure, as like as bleaching gel exposed to hal ogen lamp over 20 seconds, the pulpal temperature rised to $3^{\circ} \mathrm{C}$, while for 60 seconds it was incresead up to $4.8^{\circ} \mathrm{C}$, what can suggest that the light activation over long periods can enhance the risk of pulpal damages. ${ }^{33}$

Priority, this study focused on intrapulpal temperature changes and not the histological changes, it is also important to consider that this study was conducted in vitro and has some limitations that could not exactly simul ate the conditions invivo, where there is the intrapulpal blood circulation, which is able to dissi pate the heat before intrapul pal cells damage occur and the natural movement of fluid, pul pal fluid through enamel and dentin is capable of preventing transfer of heat to the pulp tissue, which cannot be simulated in the laboratory. 
Analysis of the Pulp Chamber Temperature of Teeth Submitted to Light Activation with and without Bleaching Gel

\section{CONCLUSION}

It was concluded that the temperature of the pulp chamber of teeth light-activated with bleaching gel showed a significant increase compared to light-activated without the use of whitening gel. The temperature of the pulp in teeth submitted to light activation with LED/L aser showed a significant increase, followed by the devices J et Light 4000 Plus, Curing Light X L 3000 and $B$ right $M$ ax. It was al so observed that the intrapulpal temperature rise is directly proportional to increased exposure time of activation.

\section{REFERENCES}

1. Kugel G, Kastali S. Tooth-whitening efficacy and safety: A randomized and controlled clinical trial. Compendium of Continuing Education in Dentistry Jun 2000 (Supplement 29):S16-21;quiz S42.

2. Papathanasiou A, Kastali S, Perry RD, Kugel G. Clinical evaluation of a $35 \%$ hydrogen peroxide in-office whitening system. Compendium of Continuing Education in Dentistry A pr 2002;23(4):335-8, 40, 43-4 passim; quiz 48.

3. Goldstein RE. In-office bleaching: Wherewe camefrom, where we are today. J A m Dent A ssoc A pr 1997;128 (Suppl):11S-15S.

4. Torres CR, Caneppele TM, A rcas FC, Borges A B. In vitro assessment of pulp chamber temperature of different teeth submitted to dental bleaching associated with LED/laser and halogen lamp appliances. General Dentistry Jul-A ug 2008; 56(5):481-86; quiz 7-8, 95-96.

5. Buchalla W, Attin T. External bleaching therapy with activation by heat, light or laser: A systematic review. Dental M aterials M ay 2007;23(5):586-96.

6. Jones AH, Diaz-A rnold AM, Vargas MA, Cobb DS. Colorimetric assessment of laser and home bleaching techniques. J ournal of Esthetic Dentistry 1999;11(2):87-94.

7. Torres CRG, Batista GR, Cesar PD, B arcellos DC, Pucci CR, Borges $A B$. Influence of the quantity of coloring agent in bleaching gels activated with LED/LASER appliances on bleaching efficiency. European journal of esthetic dentistry 2009;4(2):178-86.

8. Schumb WC, Satterfield CN, W entworth RL. Hydrogen peroxide. N ew Y ork: Reinhold 1955.

9. Attin $T, B$ uchalla W, W iegand $A$ (Eds). Clinical issues of tooth whitening therapies. Adhesion, ceramics and bleaching: $A$ critical evaluation 2006; São Paulo, B razil. A cademy of Dental $M$ aterials.

10. M attos I, Shiraishi K, B raz A, Fernandes J. Hydrogen Peroxide, Importance and determination. Quimica Nova 2003;26(3): 373-80.

11. Cohen SC. Human pulpal response to bleaching procedures on vital teeth. J ournal of Endodontics M ay 1979;5(5):134-38.

12. Goldstein R, Garber D. Complete dental bleaching. Chicago: Quintessence B ooks 1995.

13. Frysh $H$, Bowles $W H, B$ aker $F$, Rivera-Hidalgo $F$, Guillen $G$. Effect of $\mathrm{pH}$ on hydrogen peroxide bleaching agents. J Esthet Dent 1995; 7(3):130-33.

14. Zach L, Cohen G. Pulp response to externally applied heat. Oral Surgery, Oral Medicine, Oral Pathology, Oral Radiology and Endodontology A pr 1965;19:515-30.
15. B aik JW , R ueggeberg FA, L iewehr FR. Effect of light-enhanced bleaching on in vitro surface and intrapulpal temperature rise. J ournal of Esthetic Restorative D entistry 2001;13(6):370-78.

16. Torres $C R G$, Borges $A B, K$ ubo $C$, Gonçalves $S, A$ raújo $R$, Celaschi $S$, et al. Dental bleaching associated to LED/Laser hybrid sources. São Paulo: Editora Santos; 2007.

17. Bowles WH, Ugwuneri Z. Pulp chamber penetration by hydrogen peroxide following vital bleaching procedures. J ournal of Endodontics A ug 1987;13(8):375-77.

18. W iegand $A, V$ ollmer $D$, Foitzik $M, A$ ttin $R, A$ ttin T . Efficacy of different whitening modalities on bovine enamel and dentin. Clinical Oral Investigations J un 2005;9(2):91-97.

19. Crim FF. B ond-selected chemistry: V ibrational state control for photodissociation and bimolecular reaction. J ournal of Physical Chemistry 1996;100(31):12725-34.

20. Sun $\mathrm{G}$. The role of lasers in cosmetic dentistry. Dental Clinics of North A merica 2000;44:831-50.

21. Chen J, X uJ, Shing C. Decomposition rate of hydrogen peroxide bleaching agents under various chemical and physical conditions. J ournal of Prosthetic D entistry 1993;69(1):46-48.

22. Wetter NU, B arroso M C, Pelino JE. Dental bleaching efficacy with diode laser and LED irradiation: A $n$ in vitro study. Lasers in Surgery and M edicine 2004;35(4):254-58.

23. Dostalova T, Jelinkova H, Housova D, Sulc J, Nemec M, $M$ iyagi $M$, et al. Diode laser-activated bleaching. Brazilian Dental J ournal 2004;15(Special N umber):S13-18.

24. Sulieman M, Rees JS, Addy M. Surface and pulp chamber temperature rises during tooth bleaching using a diode laser: $A$ study in vitro. Brazilian Dental Journal 10 Jun, 2006; 200(11):631-34.

25. Z wathen B, Fife C, L udlow T. A bsorbance of light and heat by tooth bleaching agents. J ournal of Dental Research 1998;77(A).

26. Sulieman M, A ddy M, Rees JS. Surface and intra-pulpal temperature rises during tooth bleaching: $A n$ in vitro study. B razilian Dental J ournal. 9 J ul 2005;199(1):37-40.

27. $Y$ azici $A R, K$ hanbodaghi $A$, Kugel $G$. Effects of an in-office bleaching system (ZOOM ) on pul p chamber temperature in vitro. J ournal of Contemporary Dental Practice 2007;8(4):19-26.

28. Bengel WM. Digital photography and the assessment of therapeutic results after bl eaching procedures. J ournal of Esthetic Restorative Dentistry 2003;15 (Supplement 1):S21-32; discussion $\mathrm{S}$.

29. Fraser T, Banks A. Color: la guía más completa. Barcelona: Evergreen 2004.

30. Castanho GM, Zamboni SC, Torres CR. Influence of gel color on in vitro surface and intrapulpal temperature rise during blue light-activated tooth bleaching. General Dentistry M ar-A pr 2009;57(2):146-50.

31. Gama L M F, Santos JRC, Torres CRG, B orges A B, Gonçalves $S E P, C$ elaschi $S$ (Eds). Evaluation of pulpal temperature increase in tooth bleaching associated to different light sources. B razilian Oral Research 2005.

32. Eldeniz AU, Usumez A, Usumez S, Ozturk N. Pulpal temperature rise during light-activated bleaching. Journal of B iomedical $M$ aterials R esearch (Part B ): A pplied B iomaterials Feb 15, 2005; 72(2):254-59.

33. Goodis HE, W hite J M, A ndrews J, W atanabe L G. M easurement of temperature generated by visible-light-cure lamps in an in vitro model. Dental M aterials J ul 1989;5(4):230-34. 